\title{
Demo Abstract: A Long-Lifetime Sensor Platform for a Reliable Internet of Things
}

\author{
Neal Jackson \\ University of California, Berkeley \\ neal.jackson@berkeley.edu
}

\author{
Joshua Adkins \\ University of California, Berkeley \\ adkins@berkeley.edu
}

\author{
Prabal Dutta \\ University of California, Berkeley \\ prabal@berkeley.edu
}

\begin{abstract}
Today, most energy harvesting sensors rely on capacitors to buffer small amounts of energy as they intermittently work through a sensing task. While the utilization of capacitors for energy storage affords these systems indefinite lifetimes, their low energy capacity necessitates complex intermittent programming models for state retention and energy management. Recent advances in battery technology lead us to reevaluate the impact that increased energy storage capacity may have on the necessity of these programming models and the reliability and lifetime of energy harvesting sensors.

Permamote, presented at IPSN 2019, is designed to explore the benefits of larger capacity energy harvesting Instead of a capacitor, Permamote utilizes a small lithium battery to store harvested energy. The inclusion and size of this battery was determined based on device reliability and lifetime modelling using real indoor solar irradiance traces. Permamote additionally includes a backup, nonrechargeable battery that allows continuous operation even for long periods of no available harvestable energy. In this demo, we present Permamote performing continuous and reliable sensing over a Thread (6LoWPAN 802.15.4) mesh network. Additionally, we show the end-to-end cloud infrastructure supporting connected Permamotes, with the intention of showing that energy harvesting with higher capacity enables more capable sensing.
\end{abstract}

\section{CCS CONCEPTS}

- Computer systems organization $\rightarrow$ Sensor networks; $\bullet$ Hardware $\rightarrow$ Sensors and actuators; Batteries; Reusable energy storage; Energy distribution; • Software and its engineering $\rightarrow$ Power management;

\section{KEYWORDS}

Energy Harvesting, Sensor Network, Battery, Capacity

\section{PERMAMOTE PLATFORM}

Permamote, presented at IPSN 2018 [1], is an energy harvesting sensing platform with an integrated processor, BLE/802.15.4 radio,

For questions email neal.jackson@berkeley.edu

Software and hardware is open source at github.com/lab11/permamote

Permission to make digital or hard copies of part or all of this work for personal or classroom use is granted without fee provided that copies are not made or distributed for profit or commercial advantage and that copies bear this notice and the full citation on the first page. Copyrights for third-party components of this work must be honored.

For all other uses, contact the owner/author(s).

IPSN '19, April 16-18, 2019, Montreal, QC, Canada

(c) 2019 Copyright held by the owner/author(s)

ACM ISBN 978-1-4503-6284-9/19/04.

https://doi.org/10.1145/3302506.3312491

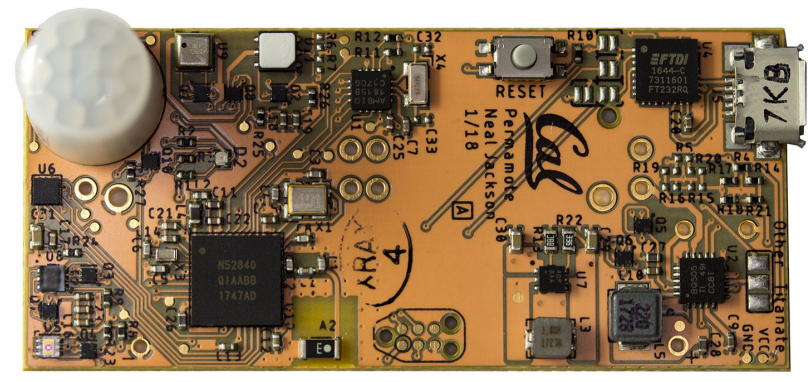

Figure 1: Permamote is an energy harvesting platform with an integrated processor and BLE/802.15.4 radio. Permamote hosts many sensors, including illuminance, temperature, humidity, pressure, motion (PIR), and acceleration.

and a variety of environmental, light, and occupancy sensors. The Permamote hardware is shown in Figure 1.

\subsection{Predictive Modelling}

To determine an optimal secondary energy storage size for Permamote, we perform numerical modelling for the behavior of an energy harvesting system like Permamote [1]. We conclude that a solar energy harvesting design should possess at least 1-10 $\mathrm{mWh}$ of storage.

\subsection{Hardware Design}

Permamote is powered by an energy harvesting front end that realizes the benefits of using batteries. This harvesting architecture is shown in Figure 2. The harvesting power supply is enabled by the TI BQ25505 energy harvesting IC, which is designed to harvest energy while monitoring both rechargeable and backing energy stores, switching between them at user-configurable voltages [4]. A $20 \mathrm{mAh}(48 \mathrm{mWh}$ ) LTO battery is charged by an amorphous silicon solar panel. Permamote only uses a portion of available cell capacity to reduce cell wear, totalling to over $10 \mathrm{mWh}$. Permamote also incorporates a backup non-rechargeable battery to maintain operation during periods of no available energy. In designing Permamote, we search for and use the newest and lowest power components. Permamote incorporates the Nordic NRF52840 SoC over the commonly used MSP430FR series because of its higher active efficiency and similar sleep power. The NRF52840 also has an integrated $2.4 \mathrm{GHz}$ radio, which can perform BLE and 802.15.4 simultaneously. The 
NRF52840 is actively supported by Tock OS [2], introducing the possibility of its use on an energy harvesting platform. Permamote features an accelerometer and illuminance, light color, temperature, humidity, pressure, and motion (PIR) sensors. Additionally, it has an onboard real-time-clock, enabling accurate and inexpensive timekeeping.

\subsection{OpenThread Networking}

The Permamote platform utilizes OpenThread [3], to establish data backhaul. Permamotes act as Thread Sleepy End Devices (SEDs), and connect to an existing Thread mesh. Outgoing packets from Permamotes on the Thread network are routed through a Thread Border Router. OpenThread provides IPv6 datagram primitives, enabling end-to-end routing of Permamote packets to an ingress server as well as the use of datagram-based protocols like NTP and DNS to periodically update the onboard RTC time and resolve addresses for NTP servers and data endpoints.

\subsection{Cloud Infrastructure}

The cloud infrastructure for a Permamote deployment provides a data endpoint for incoming Permamote data, an interface to interact with the data, and a method for periodic Permamote software updates. A generic pub/sub interface is exposed by the data endpoint, and users can subscribe to relevant Permamotes and sensor streams. The update service fields periodic requests from deployed Permamotes and supplies updated application binaries. Update packages are signed with the update server's private key, and verified on a device before install.

\section{DEMO}

We demonstrate a multiple device deployment of Permamotes, both locally and a remote deployment in buildings on UC Berkeley's campus. We visualize incoming data from these deployments and demonstrate periodic NTP and DNS queries. We also illustrate the design and features of our cloud infrastructure, with a focus on how a manager of a Permamote deployment would collect data and remotely update devices in the field.

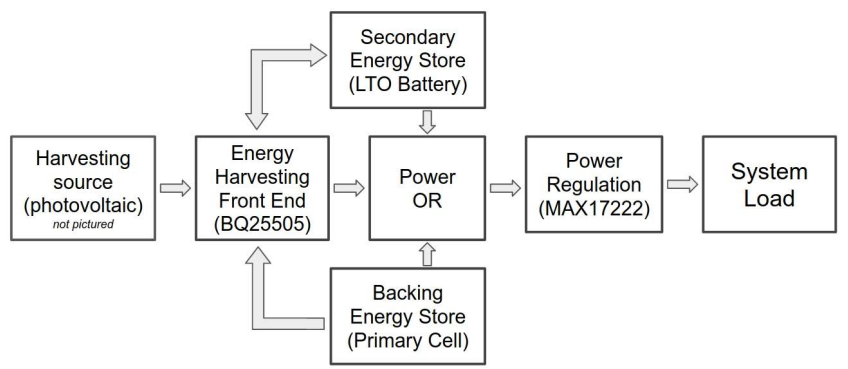

Figure 2: Harvesting and storage architecture. The Permamote power supply architecture is informed by numerical modelling performed in [1]. An LTO battery is recharged by a solar panel. When the battery is depleted, a backup non-rechargeable cell powers the system, providing reliability and preventing intermittency.

\section{ACKNOWLEDGMENTS}

This work was supported in part by the CONIX Research Center, one of six centers in JUMP, a Semiconductor Research Corporation (SRC) program sponsored by DARPA. Additionally, this material is based upon work supported by the National Science Foundation under grant numbers CNS-1824277 and DGE-1106400, and NSF/Intel CPS Security under grant CNS-1822332.

We would like to thank our anonymous reviewers for their valuable feedback, our shepherd Koen Langendoen, and Jonathan Hui and the OpenThread development team for their timely support.

\section{REFERENCES}

[1] N. Jackson et al. 2019. Capacity over Capacitance: Exploiting Batteries in Energy Harvesting Sensors (IPSN'19).

[2] A. Levy et al. 2017. Multiprogramming a $64 \mathrm{kB}$ Computer Safely and Efficiently. In Proceedings of the 26th Symposium on Operating Systems Principles.

[3] Nest Labs. 2019. OpenThread. https://openthread.io/.

[4] Texas Instruments. 2015. BQ25505 Datasheet. http://www.ti.com/lit/ds/symlink/ bq25505.pdf. 